\title{
Trazos, referencias geométricas y recursos gráficos ocultos en monumentos funerarios: el mausoleo del cardenal Juan de Cervantes en contexto
}

\author{
Strokes, geometric signs and hidden graphic devices in funeral \\ monuments: Cardinal Cervantes`mausoleum contextualized
}

Teresa LAGUNA PAÚL

Universidad de Sevilla

ORCID: http://orcid.org/0000-0003-3266-5552 / teresalaguna@us.es

DOI: http://dx.doi.org/10.18002/da.v0i19.6237

Recibido: 9-IV-2020

Aceptado: 12-VI-2020

RESUMEN: La investigación estudia los recursos gráficos ocultos del sepulcro del cardenal Juan de Cervantes realizado por Lorenzo Mercader (Lorenzo Mercadante de Bretaña). Las tramas geométricas dibujadas por este artista en este túmulo funerario guiaron la realización de sus trabajos escultóricos, desde el diseño de la microarquitectura al del corte y la talla de todas las piezas de alabastro en el taller. Las referencias gráficas incisas en la microarquitectura presentan características equiparables a los dibujos de ejecución o monteas de la cantería y arquitectura gótica.

Palabras clave: Trazos geométricos; Recursos gráficos; Escultura funeraria; Microarquitectura gótica; Mercadante de Bretaña; Sepulcro cardenal Cervantes; Catedral Sevilla.

ABSTRACT: This paper studies a series of hidden graphic devices in Cardinal Cervantes`s tomb, a work by Lorenzo Mercader (Mercadante de Bretaña). The geometric traces carved by this artist on the tumulus opened the way to all other items designed for this burial place, from its micro-architecture to the various sculptures prepared and carved in alabaster in his own workshop. The graphic signs indented on the micro-architectural frame bear a strong resemblance to the outlines and designs found on the stonework and gothic architectural features of the tomb.

Keywords: Geometric strokes; Graphic devices; Tomb sculpture; Gothic micro-architecture; Mercadante de Bretaña; Cardinal Cervantes's tomb; Seville's cathedral.

El sepulcro del cardenal Juan de Cervantes (Lora del Río/Sevilla 1382 - Sevilla 1453) de la catedral de Sevilla es una obra singular en la historia de la escultura gótica del siglo $\mathrm{XV}^{1}$. Un magnífico túmulo funera-

\footnotetext{
${ }^{1}$ El presente artículo se ha elaborado en el marco del Grupo de investigación Laboratorio de Arte (HUM-210) y de los proyectos "El patronazgo artístico en el Reino de Castilla y León (1230-1500). Obispos y catedrales I y II" (HAR2013-44536-R y HAR2017-88045-P) financiado por el Ministerio Economía y Competitividad y cofinancia-
}

rio de carácter internacional que manifiesta la trayectoria vital de su promotor y de su artífice, quien talló las virtudes del prelado

do con fondos FEDER. Un avance de este trabajo fue presentado al III Congreso Internacional do Tardo-Gótico. Da Traça à edificaçao a arquitetura dos séculos XV e XVI em Portugal e na Europa (Universidade de Lisboa, 20-22 noviembre 2017); agradezco a Carmen Pérez Lázare su ayuda para resaltar gráficamente los trazados ocultos y a Enrique Rabasa sus sugerencias para definir los términos gráficos de este túmulo funerario. 
en la inscripción del paño funerario y se vinculó a su perpetua memoria con el epígrafe del basamento: "Lorenzo Mercadante de Bretaña entalló este bulto". Con esta suscripción el escultor salvaguardó la autoría de esta obra excepcional, la primera conservada de los trabajos que realizó en la península Ibérica entre 1446 y $1468^{2}$.

Este epígrafe en caracteres góticos siempre fue visible $y$, aunque sus primeras noticias documentales las publicó José Gestoso en 1890, fue Manuel Gómez Moreno quien aportó referencias sobre el origen de este escultor que amplió Diego Angulo cuando fechó los trabajos del sepulcro entre 1453 y $1458^{3}$. Los pagos conservados de 1454 y 1458 y el conocimiento pormenorizado del mausoleo, desmontado y restaurado en 2003$2004^{4}$, deparó importantes avances en las

\footnotetext{
${ }^{2}$ José Goñi Gaztambide, "Cervantes, Juan de", en Diccionario de Historia Eclesiástica de España. Suplemento I, coord. por Quintín Aldea Vaquero y Tomás Marín (Madrid: Instituto Enrique Florez- CSIC, 1987), 124-128. Teresa Laguna Paúl, “Lorenzo Mercadante de Bretaña (documentado 1446-1468)", en Artistas andaluces y artífices del arte andaluz. El ciclo humanista. Desde el último Gótico al fin del Barroco, coord. por Clotilde Lechuga Jiménez (A Coruña: Ediciones Comunitarias, 2017), 290-325.

${ }^{3}$ José Gestoso y Pérez, Sevilla monumental y artística. Historia y descripción de todos los edificios notables, religiosos y civiles que existen actualmente en esta ciudad y noticia de las preciosidades artísticas y arqueológicas que en ellos se conservan (Sevilla: Tip. El Conservador, 1890), T. II, 520. Manuel Gómez Moreno, “JJooskén de Utrech, arquitecto y escultor?", Boletín de la Sociedad Castellana de Excursiones, V (1911), 63-66. Diego Angulo Iñiguez, "Sepulcro del cardenal Cervantes en la catedral de Sevilla", en La Escultura en Andalucía (Sevilla: Laboratorio de Arte, 1928), vol. I, 44-58. Diego Angulo Íñiguez, “Bordados de estilo eyckiano del sepulcro del cardenal Cervantes de la Catedral de Sevilla", en Mélanges Hulin de Loo (Bruxelles: Librairie Nationale d'Art et d'Historire, 1931), 1-4. Herman Stegmann y Diego Angulo Íñiguez, La escultura en Occidente (Barcelona: Bruguera, 1936), 182-183.
}

${ }^{4}$ Restauración sufragada por la Catedral de Sevilla y realizada por la empresa CORESAL, con la supervisión de Concha Cirujano del IPCE, Alfonso Jiménez y Teresa Laguna por la catedral de Sevilla. Archivo Catedral de Sevilla, CORESAL (Conservación y Restauración de Bienes Culturales), Memoria de la restauración del sepulcro del cardenal Cervantes de la catedral de Sevilla, Enero 2005. Álvaro Jiménez Sancho y Alfonso Jiménez Martín, “La circunstancias que rodearon este encargo permitiéndome investigar en profundidad respecto al tiempo invertido en su realización y a su técnica escultórica (Fig. 1).

La presencia documental de este escultor en Sevilla desde el mes de enero de 1454 confirma que la catedral hispalense tenía referencias suyas en fechas cercanas a la firma del testamento del cardenal Juan de Cervantes el 16 de noviembre de 1453 o inmediatas a su fallecimiento nueve días más tarde, cuando sus albaceas decidieron inhumarlo en una sepultura temporal para posteriormente trasladar sus restos a un mausoleo contratado con un escultor de prestigio ${ }^{5}$. La elección recayó en "Lorenço Mercader", Mercadante de Bretaña, un artista formado en las cortes francesas e internacionales que se trasladó a la península Ibérica en busca de unas favorables expectativas laborales donde estuvo contratado en el taller de Fontaner de Usesques en Zaragoza entre 1446 y $1448^{6}$ y cinco años después acudió a esta llamada de la catedral de Sevilla, ciudad en la que está documentado hasta $1468^{7}$.

restauración del sepulcro del cardenal Cervantes de la catedral de Sevilla", en En el umbral de la memoria. Actas de las XIII jornadas internacionales de intervención en el patrimonio histórico-artístico. Logroño 3-6 noviembre 2005, (Logroño: COAR, 2005), 303-315.

${ }^{5}$ Teresa Laguna Paúl, “Un escultor para un cardenal. Lorenzo Mercadante de Bretaña y el sepulcro de Juan de Cervantes: nuevas lecturas documentales", De Arte, no 16 (2017), 12-14 y 21-26, http://dx.doi.org/10.18002/ da.v0i16.5000. Teresa Laguna Paúl, "Memoria funeraria y patronazgo de Juan de Cervantes en la catedral de Sevilla. Mercadante de Bretaña y las obras de la capilla de san Hermenegildo", en Obispos y catedrales. Arte en la Castilla Bajo Medieval, coord. por María Victoria Herráez Ortega, Concepción Cosmen Alonso, María Dolores Teijeira Pablos y José Alberto Morais Morán (Berna: Peter Lang, 2018), 75-120.

${ }^{6}$ Javier Ibáñez Fernández y Diego Domínguez Montero, "Antes de Sevilla: Lorenzo Mercader (Mercadante) de Bretaña en Zaragoza (1446-1448). Transferencias e intercambios entre las Coronas de Aragón y Castilla a mediados del siglo XV", Artigrama, nº 30 (2015), 169-191.

${ }^{7}$ Laguna Paúl, “Lorenzo Mercadante”, 291-325. Teresa Laguna Paúl, "The Virgen del Buen Fin in the context of the sculptural oeuvre of Lorenzo Mercadante de 


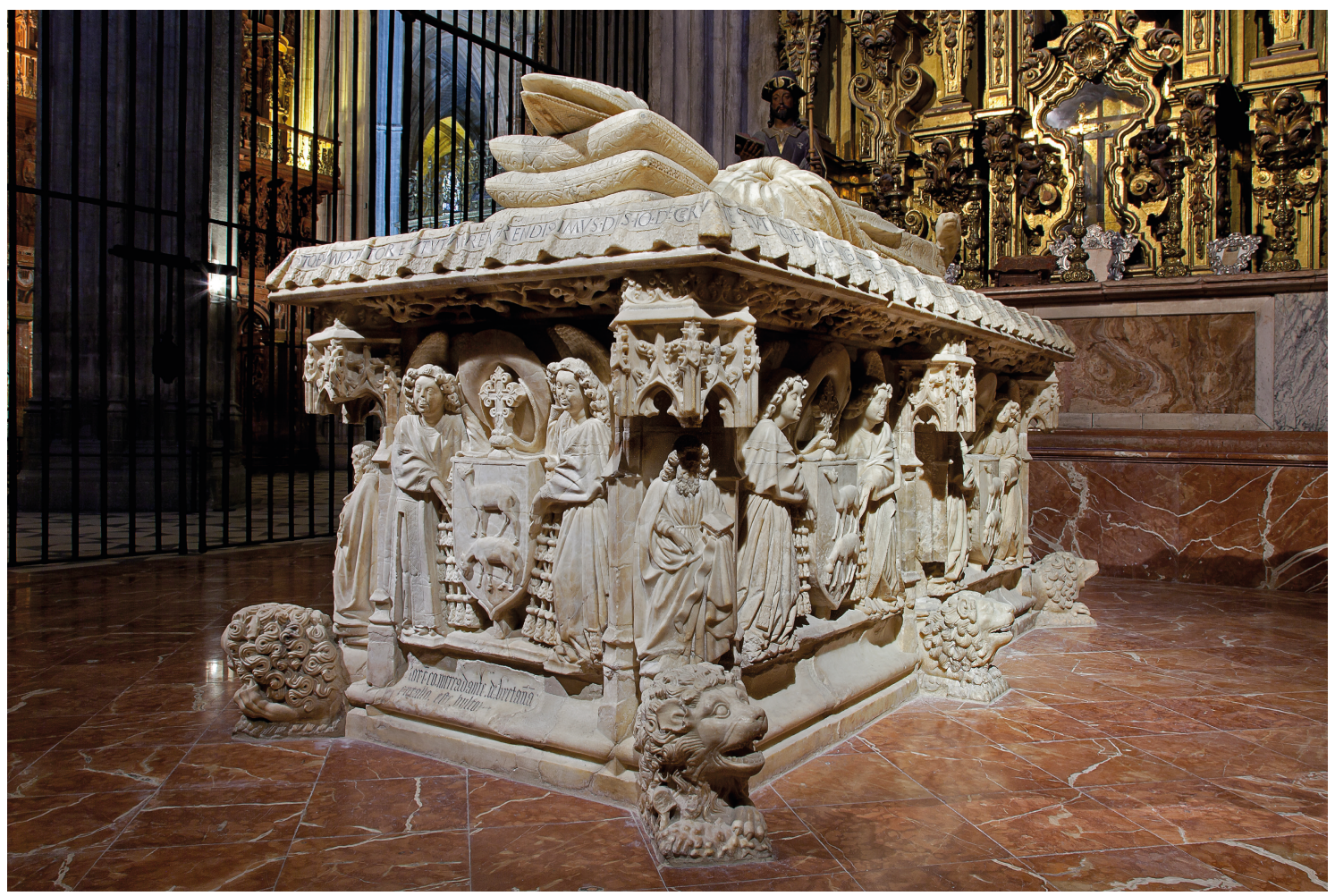

- Fig. 1. Lorenzo Mercadante de Bretaña. Monumento funerario del cardenal Juan de Cervantes (doc. 14531458). Catedral de Sevilla, capilla san Hermenegildo. Foto de la autora.

Los contactos y transferencias artísticas entre la catedral de Sevilla y los maestros activos en la Corona de Aragón se remontan, documentalmente, a las contrataciones de los arquitectos Ysambarte y Carlín quienes trabajaron en la obra de su templo gótico en 1433-1434 y 1435-1447, respectivamente, según la documentación de archivo conocida. La reputación y valía del último ya le hizo acudir a Valencia en 1429, cuando era maestro mayor de la catedral de Lérida, para tasar unas ventanas bíforas de la Sala del Consejo de esta ciudad por lo que se piensa que maestre Carlín mantendría durante toda su vida relaciones y vínculos profesionales con los maestros activos en las diócesis de Barcelona, Lérida, Valencia y Zaragoza ${ }^{8}$.

Bretaña", en Nicola Jennings y Teresa Laguna, Lorenzo Mercadante de Bretaña. Virgen del Buen Fin (Madrid: Coll y Cortes, 2016), 49-55. Laguna Paúl, “Un escultor para un cardenal", 9-14 y 18-24.

${ }^{8}$ Amadeo Serra Desfilis, "El fasto del palacio inacabado. La casa de la ciudad de Valencia en los siglos XIV y XV", en Historia de la ciudad III. Arquitectura y transfor-
Lorenzo Mercadante es el primer escultor documentado en Sevilla en el siglo XV, su presencia en Andalucía se relaciona con el encargo de este sepulcro y, aunque carecemos de noticias, pueden establecerse varias hipótesis con relación a cuándo o cómo la catedral hispalense estableció los contactos con él o tuvo conocimiento de su valía profesional. Ante esta falta de información, Francisco Reina Giráldez pensó en la posibilidad de que fuera Juan Normant, maestro mayor de la catedral en 1453, quien facilitara sus referencias ${ }^{9} \mathrm{y}$ desde hace unos años se indagan otros contactos a través del arquitecto y escultor de la catedral de Valencia Antoni Dalmau (doc. 1435-1453), quien acompañado del cantero Joan de Caritat (doc. 1441-1464), hizo un encargo puntual para la seo hispa-

mación urbana de Valencia, coord. por Mar Alonso, Málek Murad y Francisco Taberner (Valencia: Colegio de Arquitectos de Valencia y Universidad Valencia, 2004), 90.

${ }^{9}$ Francisco Reina Giráldez, "Llegada a Sevilla y primeras obras de Lorenzo Mercadante de Bretaña", Archivo Hispalense, $\mathrm{n}^{\mathrm{o}} 215$ (1987), 143-151. 
lense en 1447 y dos años más tarde declinó el ofrecimiento del cardenal Cervantes para ser maestro mayor de la misma ${ }^{10}$. Las primeras noticias del escultor Antoni Dalmau confirman su especialización en la talla del alabastro desde 1435 cuando, formando parte del taller de Pere Joan, trabajó en la predela del retablo mayor de la catedral de san Salvador de Zaragoza hasta 1440, en que volvió a Valencia. En la capital del Turia le encargaron el portal del coro de su catedral (1440-1444) donde dirigió a un amplio grupo de canteros y tallistas en alabastro que, posteriormente, desarrollaron su actividad en varios territorios de la Corona de Aragón e incluso algunos se incorporaron al taller del retablo zaragozano al reanudarse los trabajos en 1445, ya que siempre mantuvo vínculos con la capital $\operatorname{aragonesa}^{11}$.

Estas hipótesis no excluyen, ni descartan, que el cabildo indagara y tuviera noticias de éste o de otros escultores mediante vías diplomáticas e intercambios de información eclesiástica para este encargo ${ }^{12}$. Tampoco podemos omitir que en Sevilla ya

\footnotetext{
${ }^{10}$ Mercedes Gómez-Ferrer Lozano, "El maestro de la catedral de Valencia Antoni Dalmau (1435-1453)", en Gothicmed: un museo virtual de la arquitectura gótica mediterránea, 2008, http://www.gothicmed.com/gothicmed/GothicMed/library/maestros/Antoni-Dalmau. html; disponible también en http://www.academia. edu/11010998, 12 de abril de 2012. Arturo Zaragozá Catalán, “Lenguaje gótico, tradiciones constructivas tardorromanas e inspiración bíblica: consideraciones sobre el gótico mediterráneo y la catedral de Sevilla", en La piedra postrera. $V$ Centenario de la conclusión de la catedral de Sevilla. 1 (Ponencias), coord. por Alfonso Jiménez Martín (Sevilla: Turris Fortissima, 2007), 166-172. Alfonso Jiménez Martín, Anatomía de la catedral de Sevilla, (Sevilla: Diputación Provincial, 2013), 124-127. Ibáñez Fernández y Domínguez Montero, "Antes de Sevilla", 185. Laguna Paúl, "The Virgen del Buen Fin", 49-53. Laguna Paúl, "Lorenzo Mercadante", 291-325.
}

${ }^{11}$ Mercedes Gómez-Ferrer Lozano, “La cantería valenciana en la primera mitad del siglo XV: el maestro Antoni Dalmau y sus vinculaciones con el área mediterránea", Anuario del Departamento de Historia y Teoría del Arte, 9-10 (1997-1998), 97-99.

${ }^{12}$ Laguna Paúl, “Un escultor para un cardenal”, 1114 y 18-23. Laguna Paúl, "Memoria funeraria y patronazgo", 103-109. existían monumentos funerarios con yacentes tallados en alabastro, piedra o mármol realizados, seguramente, por artistas o talleres foráneos que no permanecieron en estas tierras del Guadalquivir después de instalar, entre otros, el sepulcro de piedra policromada de Fray Álvaro Peláez (post. 1349), obispo de Silves, en el convento de santa Clara de Sevilla, el del arzobispo Don Gonzalo de Mena (†1401) de alabastro parcialmente policromado en la catedral de Sevilla y los de la familia de Pérez de Guzmán atribuidos al taller toledano de Ferrán González (1385-1410) cuyas cajas y yacijas originales no llegaron a nuestros días ${ }^{13}$. Estos sepulcros constituyen, hoy en día, testimonios importantes de otros perdidos que confirman encargos de túmulos funerarios con bultos para la ciudad de Sevilla desde mediados del siglo XIV, cuando se realizaría el del arzobispo Fray Alonso de Vargas (†1366) que todavía alcanzó a ver Félix González de León (Sevilla, 1790-1854) ${ }^{14}$.

La firma del túmulo del cardenal Juan de Cervantes indica claramente la implicación personal de Lorenzo Mercadante en la talla de la efigie de este prelado, una autoafirmación de su valía profesional y, presumiblemente, su intención por dejar constancia de su origen y formación con un grupo de escultores especializados en la realización de sepulcros con yacentes, tombiers. Una efigie fiel, un retrato realista y moderno, no exento de matizaciones de cierto ideal cristiano de una buena muerte, que tiene una factura sumamente depurada y de mayor unidad

\footnotetext{
${ }_{13}$ María Teresa Pérez Higuera, "Ferrand González y los sepulcros del taller toledano (1385-1410)", Boletín del Seminario de Estudios de Arte y Arqueología, no 44 (1978), 129-142. Teresa Laguna Paúl, "La escultura", en Andalucía Gótica, coord. por José Fernández López (Madrid: Encuentro, 1992), 71.

${ }^{14}$ Félix González de León, Noticia artística, histórica y curiosa de todos los edificios públicos, sagrados y profanos de esta muy noble, muy heroica e invicta ciudad de Sevilla y de muchas casas particulares con todo lo que les sirve de ornato artístico, antigüedades inscripciones y curiosidades quie contienen (Sevilla: Imp. J. Hidalgo y Cía, 1844), T. II, 60.
} 
plástica que la yacija donde pudo contar con algún ayudante ${ }^{15}$.

Establecidos los contactos con la catedral, antes de formalizar cualquier acuerdo relativo al monumento funerario los albaceas testamentarios del cardenal y los representantes del cabildo expondrían al escultor sus preferencias estéticas e iconográficas, sus necesidades para abrir la capilla y realizar una sepultura acorde con la dignidad, con la importancia del legado y memoria de Don Juan de Cervantes en la catedral de Sevilla, su heredera. El escultor explicaría las directrices del mausoleo de alabastro con sus dimensiones, las características del zócalo, del basamento con el número de hornacinas y esculturas que cobijarían, la disposición de los relieves, del paño de la tapa y del retrato del cardenal sobre ésta. También plantearía las propiedades del alabastro más idóneo para llevarlo a cabo, sus condiciones económicas y el tiempo previsto para su realización e instalación, que habitualmente era de un año, según otros contratos contemporáneos firmados por Egas Cueman en 1458 y 1467 o por el maestre Sebastián de Toledo en $1489^{16}$.

${ }^{15}$ Joaquín Yarza Luaces, "Artista-artesano en la Edad Media hispana" en L'Artista-Artesà Medieval a la Corona d'Aragó: actes: Lleida, 14, 15 i 16 de gener de 1988, coord. por Joaquín Yarza Luaces y Francesc Fité i Llevot (Lleida: Universitat Lleida, 1999), 52 y ss. Francesca Español Bertran, "El artífice y sus habilidades. La transmisión del conocimiento artístico medieval", en Ver y crear. Obradores y mercados pictóricos en la España gótica (13501500), coord. por Matilde Miquel, Olga Pérez Monzón y Miriam Bueso (Madrid: La Ergástula, 2017), 124-132. Laguna Paúl, "Memoria funeraria y patronazgo", 103120.

${ }^{16}$ Germán Rubio e Isidoro Acemel, "El maestro Egas en Guadalupe", Boletín de la Sociedad Española de Excursiones, T. 20/3 (1912), 192-229. José María Azcárate y Rístori, Colección de documentos para la Historia del Arte en España 2. Datos histórico-artísticos de fines del siglo XV y principios del XVI, (Madrid-Zaragoza: Caja de Ahorros de Zaragoza, 1982), II, 242-244. Laguna Paúl, “Memoria funeraria y patronazgo", 114-115. Ángel Fuentes Ortiz, "La capilla de Gonzalo de Illescas en el monasterio de Guadalupe: un proyecto de Egas Cueman recuperado", Archivo Español de Arte, XC/358 (2017), 113-118.
Aprobado el diseño, cláusulas y condiciones para la factura del monumento, según la documentación conservada de 1454 y 1458, establecieron dos etapas o dos acuerdos contractuales, dos contratos, para su realización con el fin de priorizar la apertura de la capilla de san Hermenegildo sin condicionarla a la instalación completa del monumento funerario en este ámbito. A finales de noviembre de 1453 inhumaron al cardenal en una sepultura temporal y fue preciso esperar varios años para proceder a la exhumación de sus restos en el interior del túmulo de alabastro. El primero se terminó en diciembre de 1454 cuando cerraron administrativamente la cuenta de una Virgen de alabastro, la Virgen del Madroño, y del "bulto" de este prelado, después realizó la yacija porque en 1458 todavía le estaban abonando algunos de sus relieves y el monumento quedó concluido e instalado en la capilla en el transcurso del año siguiente ${ }^{17}$.

Las últimas investigaciones y el conocimiento de la realidad material del sepulcro, a partir de su restauración en 2003-2004, confirman que éste obedece a un proyecto o planteamiento unitario, realizado en sincronía con la terminación y ajuar mobiliario de esta capilla, del espacio de plegaria dotado por el cardenal en la catedral de Sevilla. La realización material de este monumento funerario tuvo, por tanto, dos momentos o etapas cronológicas que, además, explican una cierta desigualdad plástica en la ejecución de la yacija sepulcral y su ornato, cómo ya señaló Amador de los Ríos entre otros investigadores ${ }^{18}$. Estas diferencias en su factura las relacionamos con la planificación del trabajo, con el acopio del material y, presumiblemente, por la asistencia o colaboración de algún ayudante, al menos para desbastar los bolos, tallar algunos elementos arquitec-

\footnotetext{
${ }^{17}$ Laguna Paúl, "Un escultor para un cardenal”, 2426. Laguna Paúl, "Memoria funeraria y patronazgo", 114-117.

18 José Amador de los Ríos, Sevilla pintoresca o descripción de sus monumentos artísticos (Sevilla: Colom y Colom, 1844), 164.
} 
tónicos y ciertas partes de los relieves. La elaboración del monumento y la suscripción del epígrafe en el basamento evidencian una implicación total de Lorenzo Mercader en la soberbia escultura del cardenal y en la preparación de todas las piezas del túmulo, aunque carecemos de cualquier referencia relativa a la existencia de su taller ${ }^{19}$.

La tumba de Juan de Cervantes representa el velatorio, la exposición pública del fallecido en la capilla ardiente. El cardenal de Ostia, vestido con todas las prendas y ornamentos suntuosos de pontifical, descansa sobre un paño de brocado que cubre la parte superior del túmulo, conformado por seis relieves heráldicos dispuestos entre hornacinas, que cobijan las esculturas dispuestas sobre un zócalo con seis leones. Esta iconografía funeraria presente en otros sepulcros, laicos y eclesiásticos, manifiesta una exaltación de sus armas sostenidas por parejas de ángeles que parecen poco adecuadas para un príncipe de la Iglesia, como señaló Joaquín Yarza, y tuvieron continuidad en otros sepulcros hispanos de la segunda mitad del siglo XV caso, por ejemplo, el de Don Álvaro de Luna y Juana Pimentel ${ }^{20}$. Su tipología atiende a las directrices del modelo gótico nórdico con otros elementos propios del humanismo del 1400, acordes con el mecenazgo y la cultura dual de Juan de Cervantes manifiesta en la epigrafía del sepulcro: la letra gótica del zócalo con la firma de Lorenzo Mercadante convive con el epitafio tallado y embutido con mayúsculas humanísticas de betún resinoso negro que recorre el borde del paño funerario, bajo el cual destaca un extraordinario calado de racimos y zarcillos

${ }^{19}$ Laguna Paúl, "Un escultor para un cardenal”, 2426. Laguna Paúl, "Memoria funeraria y patronazgo", 109-120.

${ }^{20}$ Joaquín Yarza Luaces, "Hombres de poder, gentes del libro, "Viri; Litterati" y encargos artísticos", en $E l$ marqués de Santillana (1398-1458), los albores de la España Moderna. El humanista, coord. por Joaquín Yarza (Hondarrabia: Nerea, 2009), 16-17. Laguna Paúl, "Memoria funeraria y patronazgo", 113-114. de vides de renovada iconografía funeraria y una rana en clave de resurrección ${ }^{21}$.

SELECCIÓN DEL ALABASTRO, PREPARACIÓN DE LAS PIEZAS Y TRAZADOS GRÁFICOS

La documentación conocida omite cualquier referencia a la terminación cromática que tuvo este sepulcro y también silencia la información relativa a la selección, adquisición y transporte del alabastro hasta Sevilla que, sin duda, formaron parte de los compromisos contractuales con el escultor y alcanzarían una cifra aproximada entre el $25 \%$ y el $33 \%$ del precio establecido. Tampoco puede descartarse que, como ocurrió en otras ocasiones, adquirieran este material en alguna cantera aragonesa o, incluso, fuera el propio cardenal quien realizara un acopio o compra de alabastro, meses antes de su óbito, valiéndose de alguna persona de su confianza o de algún imaginero de acreditada reputación con quien tuviera contactos, como hizo el arzobispo Diego de Deza cuando regaló una partida de alabastro de Gerona para la peana del retablo mayor de la catedral de Sevilla en mayo de $1513^{22}$.

El tamaño de las piezas, las pautas observadas para la preparación de los trabajos escultóricos, la talla del bulto y del túmulo evidencian una depurada selección de los bolos en la cantera. Todo el alabastro es de gran pureza, de grano muy compacto y color uniforme, disponiendo siempre las zonas con aguas o vetas en la cara interna del túmulo, el área oculta al espectador. Sus características hacen pensar que procede de una

\footnotetext{
${ }^{21}$ Laguna Paúl, "Memoria funeraria", 104. Pablo Mestre Navas, "Antiguas letras para un arte nuevo. Escritura, memoria y publicidad en el sepulcro del cardenal Juan de Cervantes", Documenta \& Instrumenta, $\mathrm{n}^{\mathbf{0}} 17$ (2019), 86-87 y 90-91.

${ }^{22}$ Archivo Catedral de Sevilla, Sección I, Secretaría, Libro 8 de Autos capitulares 1513-1515, ff. 38r. Manuel Giménez Fernández, El retablo mayor de la Catedral de Sevilla y sus artistas (Sevilla: Laboratorio de Arte, 1927), 14. Juan Clemente Rodríguez Estévez, Los canteros de la catedral gótica. Del Gótico al Renacimiento (Sevilla: Diputación Provincial, 1998), 144-145.
} 
misma cantera aunque apreciamos algunas diferencias en el tono blanco del bulto respecto a las cincuenta y siete que conforman la cama con su tapete funerario. Estas características confirman que en la elección del alabastro tuvieron en cuenta los criterios técnicos de la efigie del cardenal, esculpida en cuatro grandes bloques $(270 \mathrm{~cm}$ largo y 38,38 $\mathrm{cm}$ altura máxima) y las de todas las piezas del túmulo, de 123,28 cm alto x 334,08 cm largo x 171,20 cm de fondo: el extraordinario paño mortuorio, el zócalo del basamento con sus leones, la preparación de los seis relieves y las seis esculturas del basamento cobijadas en sus tabernáculos góticos. La documentación conservada en el archivo de la catedral de Sevilla impide establecer si la adquisición de los bolos se realizó en una o en dos campañas, en cuyo caso estarían relacionadas con las características del alabastro, con los acuerdos contractuales y los calendarios de entregas concertados por los albaceas y la catedral hispalense, como heredera de Don Juan de Cervantes, con el escultor Lorenzo Mercader en $1453^{23}$.

El análisis del bajorrelieve del mantel manifiesta pequeñas irregularidades en los perfiles de la vegetación que demuestran una labra sin plantillas, directa, sobre un dibujo preliminar y una depurada preparación en cada una de las caras de los once bloques empleados en su realización. Estas piezas de $34,96 \mathrm{~cm}$ de altura conservan en sus caras internas, en las superficies del reverso y de los cortes perpendiculares, unas referencias geométricas trazadas a punzón con gran precisión, que indican, claramente, el trabajo de un escultor coordinado con su equipo que estaría encargado de desbastar y realizar las tareas de menor complejidad artística.

Los trazos ocultos también se encuentran en todas las piezas del zócalo y en los tabernáculos, donde Alfonso Jiménez indicó analogías entre sus rasguños y las superficies de las tablas de los tabernáculos de la portada del Baptisterio de la misma catedral, es-

\footnotetext{
${ }^{23}$ Laguna Paúl, "Memoria funeraria y patronazgo", $107-113$
}

tudiadas por José Antonio Ruiz de la Rosa; trazados incisos y definitorios del contorno, de la ubicación de molduras y planos, de sus proporciones, de los ejes de simetría que guiaron su talla hasta alcanzar su figura definitiva y el ensamblaje de algunas piezas del conjunto $^{24}$ (Figs. 2 y 3 ).

Estas tramas gráficas del túmulo del cardenal Cervantes permiten analizar el trazado de su microarquitectura en sintonía con los hábitos góticos señalados desde los trabajos de François Bucher ${ }^{25}$, del trazado geométrico de los lechos horizontales de las dovelas estudiadas por Robert Willis a mediados del siglo XIX, de las investigaciones relativas a la geometría gótica, de los hallazgos e investigaciones de las últimas décadas relativos a dibujo gótico cuyo catálogo continúa incrementándose en la península Ibérica ${ }^{26}$.

\footnotetext{
${ }^{24}$ Alfonso Jiménez Martín, "El otro archivo de la catedral", en Archivos de la Iglesia de Sevilla. Homenaje al archivero D. Pedro Rubio Merino, coord. por Carmen Álvarez y Manuel Romero (Córdoba: Cajasur, 2006), 765-766. José Antonio Ruiz de la Rosa, “Dibujos de ejecución. Valor documental y vía de conocimiento de la catedral de Sevilla", en La catedral de Sevilla. Fundación y fábrica de la obra nueva, coord. por Alfonso Jiménez Martín (Sevilla: Universidad de Sevilla, 2006), 342-343, figs. 5-42/5-47. Jiménez Martín, Anatomía de la catedral, 139. Alfonso Jiménez Martín, “20. Monteas de un dosel de la tumba del cardenal Juan de Cervantes, en la catedral de Sevilla", en Trazas, muestras y modelos de tradición gótica en la Península Ibérica entre los siglos XIII y XVI, coord. por Javier Ibáñez Fernández (Madrid: Instituto Juan de Herrera, 2019) 122-124.
}

${ }^{25}$ François Bucher, "Medieval architecture Dessing Methods 800-1560", Gesta, XI/2 (172), 37-51. Javier Ibáñez Fernández, "Las microarquitecturas y la generación y transmisión de las formas arquitectónicas en el mundo ibérico entre los siglos XIV al XVI, en Sevilla 1514. Arquitectos tardogóticos en la encrucijada, coord. por Begoña Alonso Ruiz y Juan Clemente Rodríguez Estévez (Sevilla: Universidad de Sevilla, 2016), 417-420. José Calvo López y Marcos Ros Sempere, “Los instrumentos de los canteros en la transición del gótico al renacimiento", en La arquitectura tardogótica castellana entre Europa y América, coord. por Begoña Alonso Ruiz (Madrid: Silex, 2011), 417-433.

${ }^{26}$ Robert Willis, "On the construction of the vaults of the Middle Ages", Transactions of the RIBA, vol. I/2 (1842), 1-74. Enrique Rabasa Díaz, Forma y construcción en piedra. De la cantería medieval a la estereotomía del siglo 


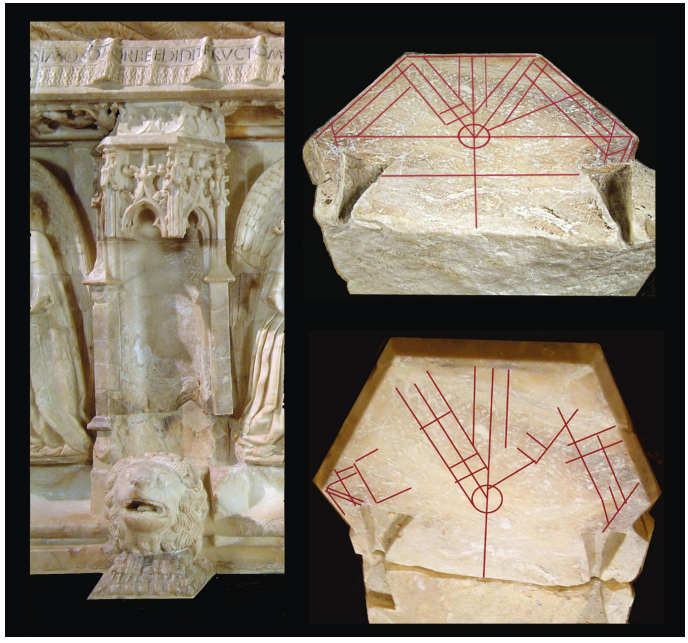

- Fig. 2. Referencias gráficas conservadas en los dos doseles centrales del mausoleo del cardenal Juan de Cervantes. Fotos de la autora.

El examen pormenorizado de estos trazos y referencias gráficas ocultas en el paño funerario, en cada pieza de las hornacinas y sus doseletes aporta luces significativas con relación a los hábitos desarrollados por los escultores góticos, ya que son escasos los testimonios de dibujos conservados en monumentos funerarios, quizás porque los desmontajes y traslados posteriores rasparan algunas superficies y eliminaran o borraran sus huellas. Aquí toda la geometría dibujada con punzón, a punta viva, consta de líneas,

XIX (Madrid: Akal, 2000), 96-140. Begoña Alonso Ruiz, "Las trazas de montea en la construcción gótica: el caso de la montea de la capilla Saldaña", en Arquitectura tardogótica en la corona de Castilla: trayectorias e intercambios, coord. por Begoña Alonso Ruiz y Fernando Villaseñor Sebastián (Sevilla: Universidad de Sevilla, 2014), 331333. Calvo López y Ros Sempere, "Los instrumentos de los canteros", 421 y ss. Javier Ibáñez Fernández, “Entre 'muestras' y 'trazas'. Instrumentos, funciones y evolución de la representación gráfica en el medio artístico hispano entre los siglos XV y XVI. Una aproximación desde la realidad aragonesa", en Arquitectura tardogótica..., 314-315. José Calvo López y Enrique Rabasa Díaz, "Construcción, dibujo y geometría en la transición entre el Gótico y Renacimiento", Artigrama, no 31 (2016), 67-86. Javier Ibáñez Fernández, "Hacia un inventario y caracterización de los instrumentos para la proyección, documentación, presentación y ejecución del Gótico en la Península Ibérica entre los siglos XIII y XVI", en Trazas, muestras y modelos de tradición gótica en la Península Ibérica, coord. por Javier Ibáñez (Madrid: Instituto Juan de Herrera, 2019), 21-32.
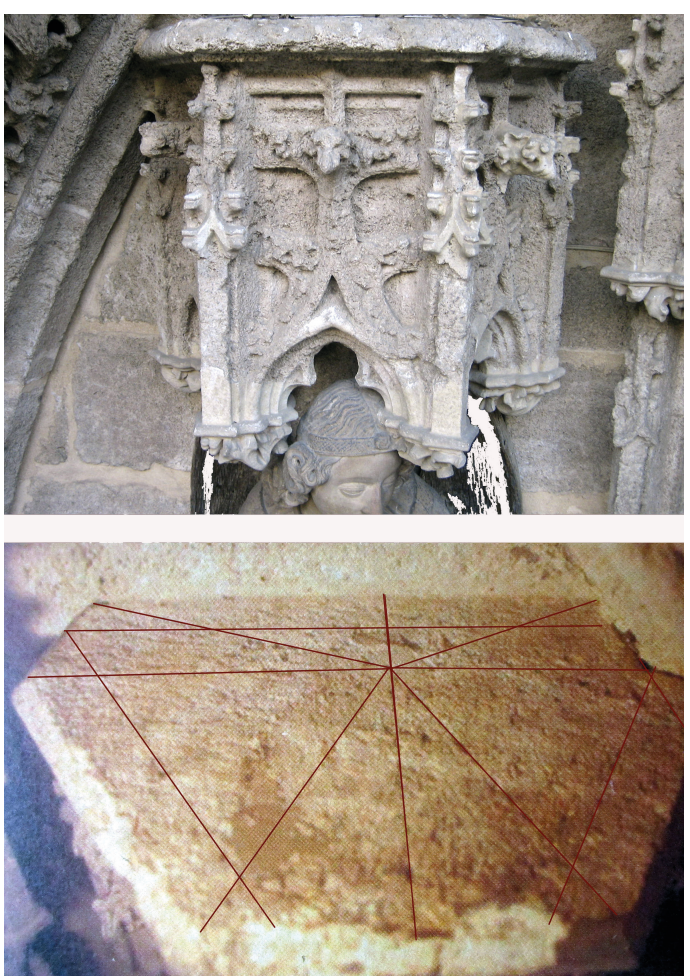

- Fig. 3. Referencias gráficas del tabernáculo izquierdo del tímpano de la puerta del Baptisterio de la catedral de Sevilla, publicado por J. A. Ruiz de la Rosa en "Dibujos de ejecución" y trazos gráficos resaltados por la autora.

círculos y centros incisos que configuran, en la superficie, la superposición gráfica de las distintas secciones horizontales. En algunas ocasiones sus huellas quedaron marcadas en la capa de yeso utilizada para asentar las piezas, lo cual confirmó la permanencia en su emplazamiento originario, sin traslados o movimientos posteriores a 1459. En su geometría encontramos trazados afines con el "plano base" definido por Ruiz de la Rosa al estudiar las monteas de los tabernáculos de las portadas occidentales de la catedral de Sevilla, pero con una mayor riqueza gráfica $^{27}$. Estos trazos gráficos determinan, definen, cada uno de los elementos arquitec-

\footnotetext{
${ }^{27}$ José Antonio Ruiz de la Rosa, Traza y simetría de la arquitectura. En la Antigüedad y Medioevo. (Sevilla: Universidad de Sevilla, 1987), 263 y ss. Ruiz de la Rosa, “Dibujos de ejecución", 310-313 y 342-346. Alfonso Jiménez Martín, “16. Trazado regulador de un tabernáculo de la puerta de la Asunción de la catedral de Sevilla", en Trazas, muestras y modelos, 118-120.
} 


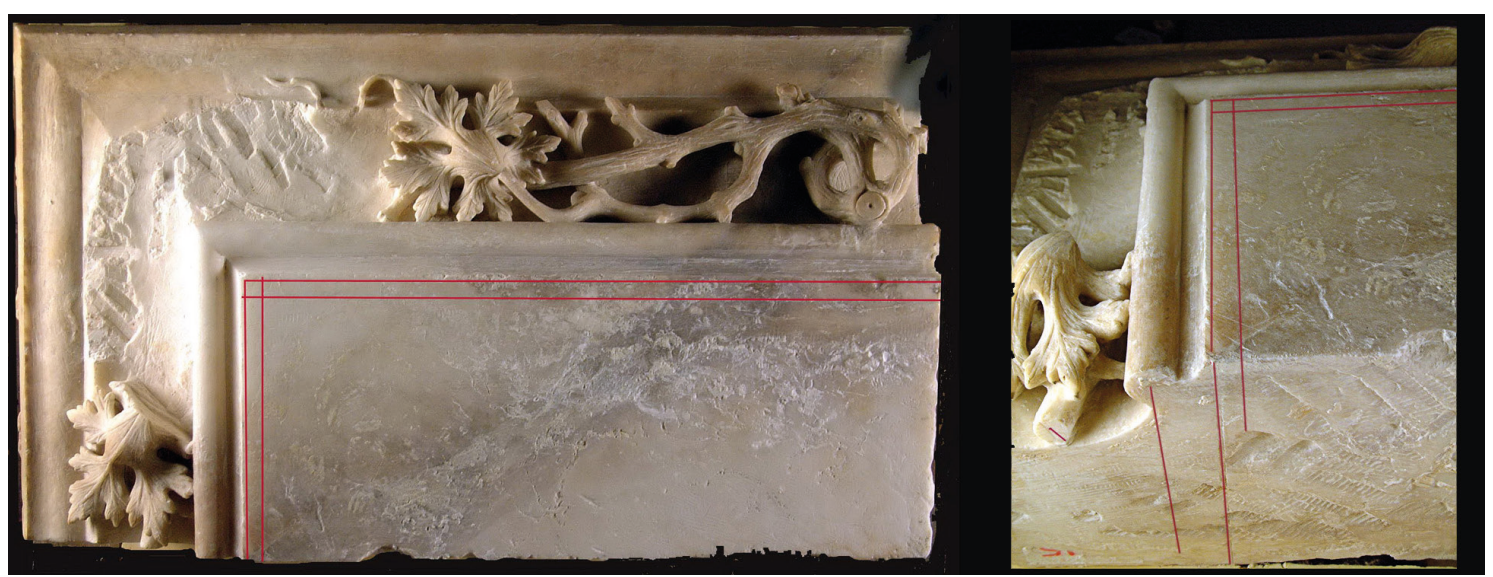

- Fig. 4. Recursos gráficos conservados en el reverso del paño funerario del mausoleo del cardenal Juan de Cervantes. Foto de la autora.

tónicos necesarios para realizar cada pieza con la técnica de talla directa, como también observamos en unas hornacinas del claustro de la catedral de San Graciano de Tours o en la iglesia de Saint-Maclou de Rouen, publicadas recientemente por Jean-Marie Guillouë ${ }^{28}$, entre otros casos como, por ejemplo, en unas basas tardogóticas del patio del antiguo Hospital de la Azabachería en Santiago de Compostela, (Santiago, Museo san Martín de Pinario). También en las zonas de los cortes verticales de algunas piezas quedan las huellas de otras referencias consumidas al esculpir los perfiles exteriores del zócalo y del extraordinario altorrelieve de zarcillos y vides, desplegado por debajo del paño funerario (Fig. 4).

Estas referencias gráficas incisas, dibujadas con un estilete o punzón, escuadra, regla y compás tienen gran precisión; sus líneas concretizan formas precisas y manifiestan una realización sin plantillas en la talla del alabastro. Representan ideas maduras para esculpir elementos arquitectónicos que desarrollan diseños omnipresentes en las empresas constructivas relacionadas con los maestros Ysambarte, Carlín y Antoni Dalmau a mediados del siglo XV. Responden a las directrices de una geometría práctica e instrumental, que no exige un conocimiento

\footnotetext{
${ }^{28}$ Jean-Marie Guillouët, Flamboyant architecture and medieval technicality (c. 1400-c.1500) (Turnhout: Brepols, 2019), 37-39, 60-62, 64-65; figs. 2.8, 2.9, 3.3 y 3.4 .
}

exhaustivo de las matemáticas pero define perfectamente los perfiles de cada pieza en la cantería arquitectónica y en la microarquitectura de los sepulcros, en los retablos de piedra o alabastro o en las custodias y construcción de otras piezas en plata y metales. El dibujo fue para los arquitectos, los escultores y los orfebres del período gótico la herramienta imprescindible para proyectar cada objeto, cada elemento, y sus fundamentos gráficos los aprendían en función de las necesidades, del desarrollo y habilidades de cada oficio, en palabras de Arturo Zaragozá29.

Estos trazos incisos localizados en los tabernáculos, zócalo y piezas del paño de alabastro del túmulo funerario de Don Juan de Cervantes fueron realizados por Lorenzo Mercader a mediados del siglo XV, evidencian su alta cualificación para esculpir una microarquitectura acorde a los postulados tardogóticos de mediados de 1400 y su análisis completa nuestros trabajos anteriores. Sus directrices gráficas no tienen parangón con la sección dibujada en uno de los pilares

\footnotetext{
${ }^{29}$ Arturo Zaragozá Catalán, “El control de la forma en la arquitectura medieval valenciana: dibujo y oficios artísticos durante los siglos XIII y XIV", en Historia de la ciudad VI: proyecto y complejidad coord. por Mar Alonso, Málek Murad y Francisco Taberner (Valencia: Colegio Oficial de Arquitectos Comunidad de Valencia y CTAV, 2010), 82. Encarna Montero Tortajada, La transmisión del conocimiento en los oficios artísticos. Valencia, 1370-1450 (Valencia: Institut Alfons el Magnanim, 2015), 287-320.
} 
del micro-claustro que rodea el basamento del monumento funerario de Juan sin Miedo y Margarita de Baviera en la cartuja de Champmol, iniciado por Claus de Werbe (†1439) y continuado por Juan de la Huerta (1443-1446) y Antoine Le Moiturier (14611470), descubiertos al desmontarlo en la última restauración de 2001-2002. Las secciones gráficas de algunas piezas de sus tabernáculos presentan trazados más próximos con los publicados de la puerta del Baptisterio de la catedral de Sevilla, o con una tabla del lapidario del claustro de san Graciano de Tours ${ }^{30}$ (Figs. 2, 3 y 5).

El mantel funerario está formado por once bloques de color uniforme, tallados en bajorrelieve siguiendo un dibujo preliminar que desarrolló el diseño de un tejido veneciano de mediados del siglo $\mathrm{XV}$, esculpido para recrear un paño de terciopelo negro con sus elementos vegetales dorados al mixtión, de los que se encontraron algunos testimonios bajo el bulto del cardenal en 2003 y reconstruí recientemente ${ }^{31}$. En la talla realista del paño Lorenzo Mercader representó los pliegues producidos por el peso del difunto, confirió volúmenes con movimiento a la caída del tejido con su fleco dorado y desplegó bajo éste un extraordinario altorrelieve con sarmientos, zarcillos, hojas de vid y racimos de uvas. Esta simbología funeraria de origen paleocristiano fue tallada con gran maestría mediante pequeños cinceles, punzones, gradinas y trépanos de arco partiendo de un dibujo y una geometría preliminar a escala 1:1 consumida en la cara anterior y conservada, parcialmente, en los lechos de los cortes perpendiculares y reverso oculto de cada pieza. En los primeros permanecen las huellas del compás que guió el trazo semicircular del bocel extremo, del centro y trazos indicado-

${ }^{30}$ Benoît Lafay, "Étude et restauration, 2001-2005", en Les tombeaux des ducs de Bourgogne. Creation, destruction, restauration, coord. por Françoise Baron, Sophie Jugie y Benoît Lafay (Dijon: Somogy editions d'art, 2009), 112, fig. 94. Rabasa Díaz, Forma y construcción, 342-344. Guillouët, Flamboyant architecture, 84-88, figs. 5.46 y 5.47

${ }^{31}$ Laguna Paúl, "Memoria funeraria y patronazgo", 118-120 y fig.12.

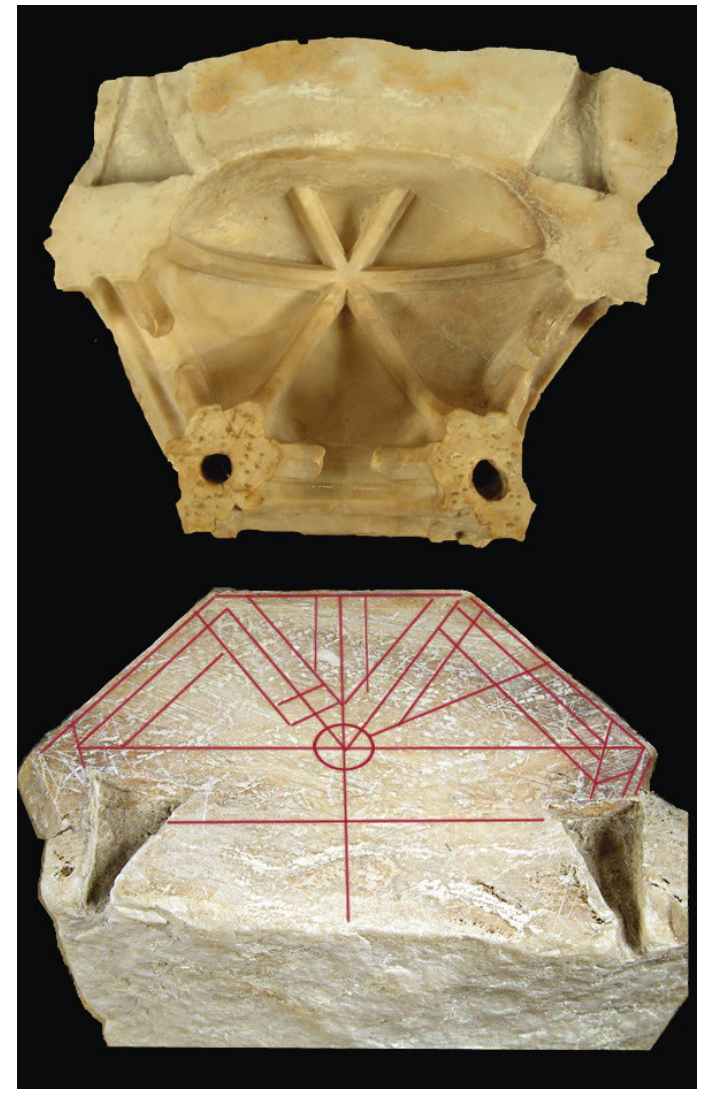

- Fig. 5. Bóveda y referencias gráficas conservadas en un dosel central del mausoleo. Fotos de la autora.

res del grosor del sarmiento calado en altorrelieve. En la superficie posterior presenta, en el límite de su perímetro, dos líneas rectas paralelas que, prolongadas en los cortes perpendiculares, establecen su correspondencia con la sección de la escocia inmediata, la que limita el bocel ultrasemicircular exterior, las referencias gráficas de la cara posterior y zonas verticales tendrían otras que definieron cada sección, cada perfil, y fueron sacrificadas al tallar el alabastro. Estas últimas continúan las tradiciones gráficas realizadas en la arquitectura real, cuyos testimonios se remontan a las basas y cornisas de época clásica con testimonios conservados, por ejemplo, en una pieza de entablamento del teatro romano de Itálica ${ }^{32}$ (Fig. 4).

${ }^{32}$ Para estos ejemplos de la arquitectura clásica: Ruiz de la Rosa, Traza y simetría, 128 y ss. Alfonso Jiménez Martín, "El tamaño sí que importa. Una historia del plano a escala", Artigrama, no 31 (2016), 47-48. 

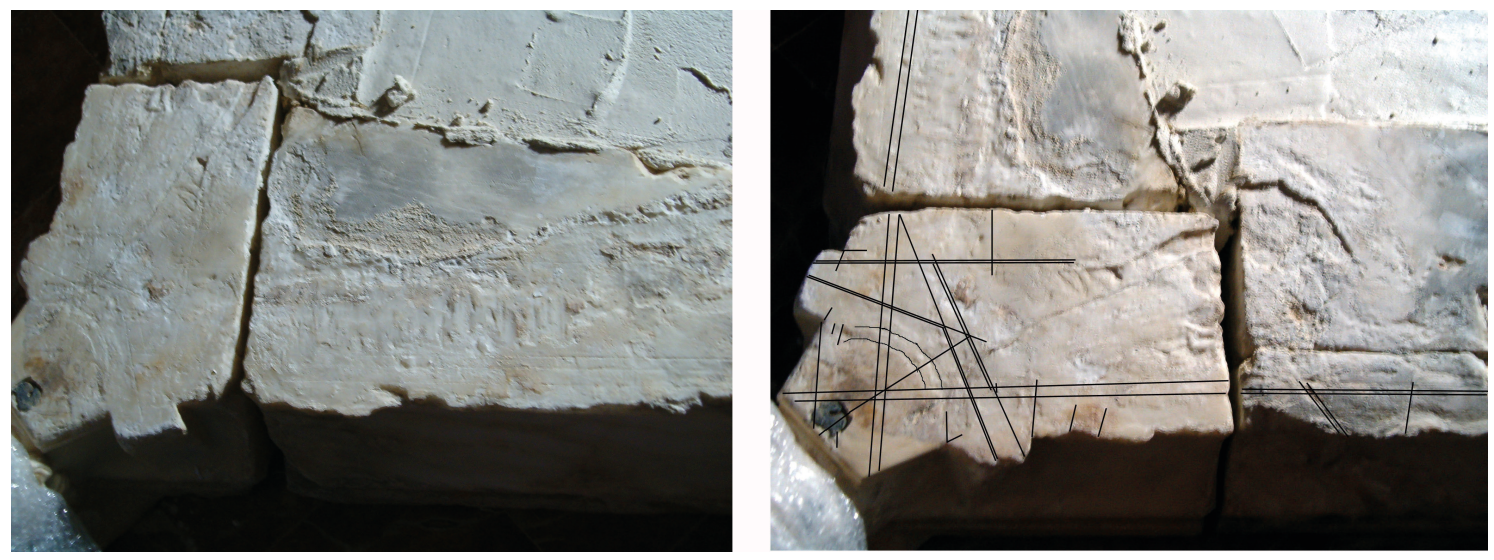

- Fig. 6. Trazos y referencias gráficas conservadas en tres piezas del zócalo del mausoleo del cardenal Juan de Cervantes. Fotos de la autora.

Los trazos de estas líneas paralelas también están dibujados en las diez piezas del basamento o zócalo que, dispuestas longitudinalmente, definieron el bocel y perfil moldurado de esta base, guiaron el montaje y el escuadre de los relieves situados encima. Estas directrices para el ensamblaje del conjunto pueden constatarse, por ejemplo, en el basamento moldurado del sepulcro de Fernando de Arce y Catalina de Sousa en la catedral de Sigüenza cuya caja está formada por diez placas con relieves, unidas en su parte superior con leñas de hierro ${ }^{33}$. Estas referencias para el montaje de los sepulcros debieron desarrollarlas habitualmente los escultores, aunque no siempre se encuentran al desmontar los monumentos funerarios ya que, por ejemplo, los sepulcros de los arzobispos Gonzalo de Mena en la catedral de Sevilla (2017-2018) y de Alonso Carrillo en Alcalá de Henares (1996-1997) carecen de estas indicaciones (Figs. 6 y 7).

La microarquitectura de cada hornacina consta de cuatro partes o piezas superpuestas: la mencionada del basamento, la capilla o tabernáculo propiamente dicho, el doselete de éste con su bóveda de crucería interna y la cornisa vegetal con crochets góticos superpuesta, que rompe la fronda interior del

${ }^{33}$ Manuel Montañés García, “Las obras de restauración. Descripción de los ámbitos, patologías y tratamientos realizados", en La catedral de Sigüenza. La puesta en práctica de un Plan Director (Madrid: Kalam-Lunwerg, 2006), 143-146.
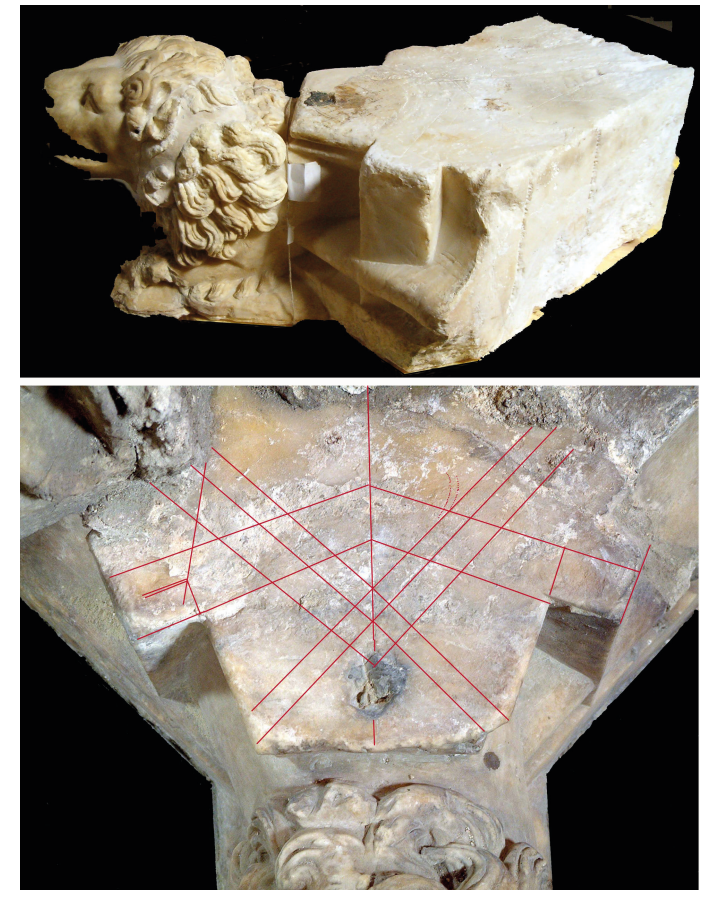

- Fig. 7. Pieza del zócalo con el torso del león y el trazado gráfico de la base del tabernáculo situado a la izquierda de la suscripción de Lorenzo Mercadante de Bretaña. Fotos de la autora.

mantel. Las diez piezas del basamento presentan las dos líneas paralelas, ya señaladas, $\mathrm{y}$ en las seis terminadas en torsos de leones existen otras de mayor precisión en correspondencia con el lecho donde asienta cada tabernáculo, porque sus pilastras atraviesan visualmente el bocel, flanqueando el torso de cada animal. La sección de cada pilastra fue dibujada en el plano base del alabastro mediante un cuadrado en las dos superficies 


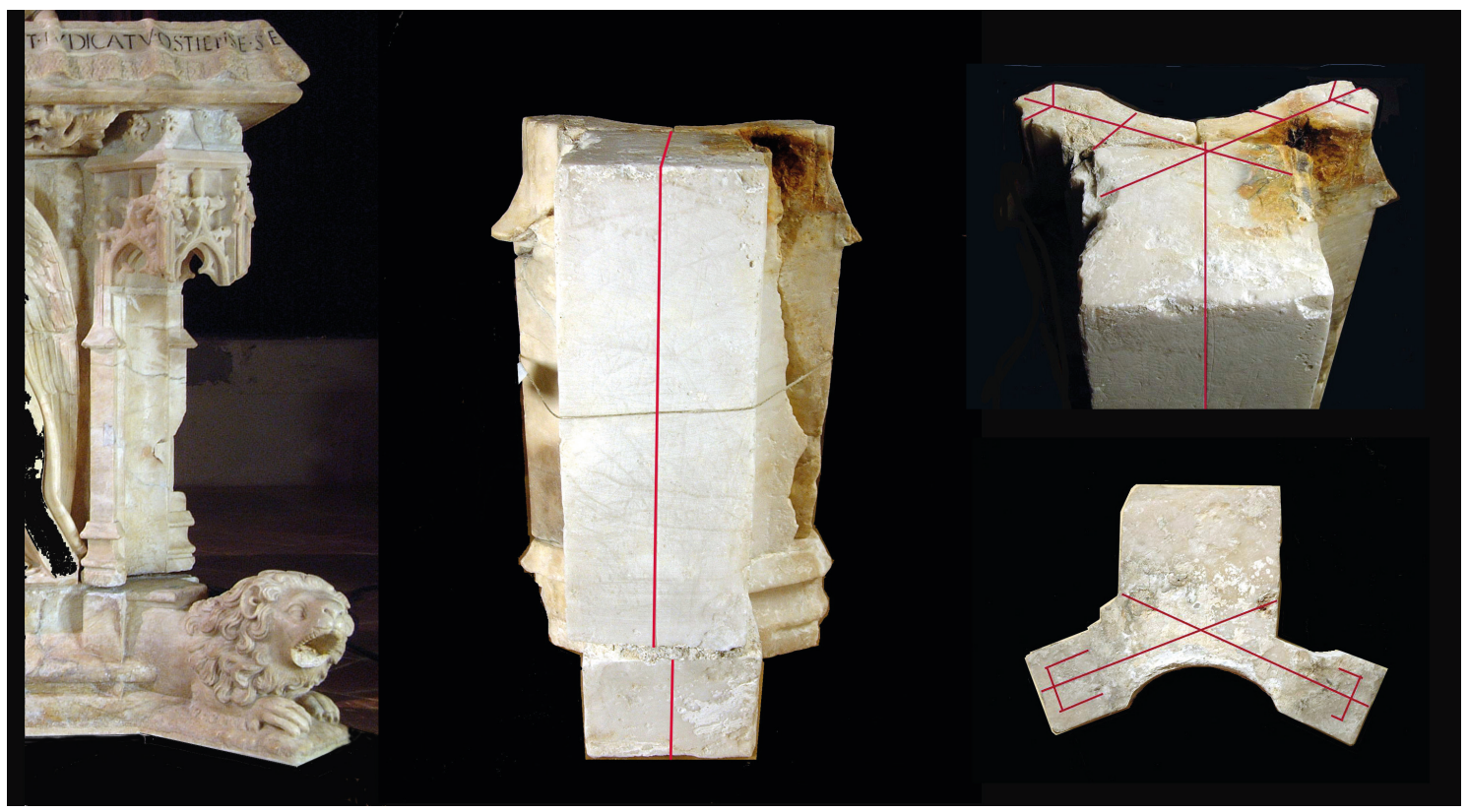

- Fig. 8.- Tabernáculo de la cabecera del mausoleo y trazados gráficos de su hornacina. Fotos de la autora.

planas de los tabernáculos y en su doselete para definir el avance de su proyección en altura y su correspondencia desde la parte baja hasta las agujas o pináculos superiores. Los trazos de estas piezas del zócalo presentan los habituales ejes de simetría radial donde confluyen las líneas directrices paralelas de otros vértices, centros y ángulos que marcaron los límites de su contorno exterior y volumen; una semicircunferencia trazada a compás estableció el perfil curvo de la posición de la hornacina y una oquedad circular recibió el perno de plomo que fijó cada escultura detrás del torso de cada león. La definición gráfica de estos últimos recuerda el dibujo inciso en el trasdós de la clave central de la capilla del Condestable de la catedral de Burgos estudiado por Enrique Rabasa $^{34}$ (Figs. 2 y 8).

Los dibujos incisos en las caras superior e inferior de la capilla del tabernáculo, que descansa sobre el basamento de leones y sirve de asiento a cada doselete, tienen una trama geométrica sencilla en correspondencia con su perfil semicircular, flanqueado por pilastras representadas con sendos cuadrados. El eje de simetría de estas piezas, dibu-

\footnotetext{
${ }^{34}$ Rabasa Díaz, Forma y construcción, 118-121.
}

jado en ambas superficies planas, se prolongó verticalmente por su cara posterior para facilitar su alineación, como observó Robert Willis al estudiar las dovelas de algunas bóvedas del gótico primitivo inglés ${ }^{35}$ (Fig. 8).

El diseño de los doseles del túmulo sigue el mismo modelo decorativo realizado en la portada del Baptisterio cuyos tabernáculos acogen el programa iconográfico de las jambas, tímpano y arquivoltas, omnipresente en las obras de Carlín y Antoni Dalmau. Sin embargo, estos de alabastro tienen y han conservado un mayor número de elementos gráficos con ciertas diferencias en su geometría, que debe obedecer a la distinta formación de sus artífices. En el trazado de esta portada Ruiz de la Rosa observó tres tramas de simetría central básicas en el periodo gótico: triángulos equiláteros en los doseles de las esculturas de las jambas, cuadrados en los de las arquivoltas y una geometría octogonal en los doseles del tímpano central ${ }^{36}$. Éstas reflejan el carácter de las bóvedas de crucería con su clave central talladas en el interior de

${ }^{35}$ Willis, "On the construction of the vaults", 11-12. Rabasa Díaz, Forma y construcción, 97-101.

${ }^{36}$ Ruiz de la Rosa, “Dibujos de ejecución. Valor documental", 342-343, fig. 5-45/48. 
los doseles de las jambas, del tímpano y en los de las arquivoltas con sus profetas esculpidos en altorrelieve; los "bolsores para los tabernáculos del arco de la portada", abonados a Nicolás Martínez y Juan Norman en $1449^{37}$ (Figs. 2, 3 y 5).

Las referencias gráficas del lecho de los dos doseles centrales del túmulo del cardenal son equiparables a la trama de triángulos existente en los tabernáculos del ángel y de san Juan Bautista del tímpano y en los de la puerta del Perdón nueva o de la Asunción de la misma catedral o, incluso, en otra tabla del lapidario del claustro de san Graciano de Tours. Sin embargo aquí presentan un mayor número de líneas descriptivas que indican, claramente, una formación distinta a la del maestro aparejador que trazó o preparó las piezas talladas por los canteros en las portadas sevillanas. Los doseles del sepulcro tienen el eje de simetría central cortado por dos líneas perpendiculares que marcan el límite de las pilastras laterales y de la bóveda gótica, cuyo centro está en correspondencia con la posición de la escultura que cobija, dibujado con un compás en la pieza baja del zócalo, de manera semejante a la geometría de los tabernáculos publicados por Jean-Marie Guillouët. La secuencia de todas las líneas paralelas trazadas en su perímetro establece las referencias para la tracería del arco quebrado y del gablete tallado con los pináculos que lo flanquean. La microarquitectura de la bóveda de crucería sexpartita, que voltea sobre los pilares y los arcos formaletes internos, tiene los nervios esculpidos con un bocel simple flanqueado por un perfil angular, la unión de sus plementos resaltada y carece de la clave tallada en los doseles de la portada del Baptisterio (Figs. 2 y 5).

La microarquitectura exterior y las referencias gráficas en los cuatro doseles de los ángulos del monumento presentan los mismos elementos, las mismas bóvedas de

\footnotetext{
${ }^{37}$ Laguna Paúl, "Las portadas del Bautismo y del Nacimiento de la catedral de Sevilla", Bienes Culturales, Revista del Patrimonio Histórico Español, no 1 (2002), 89-90 y 92.
}

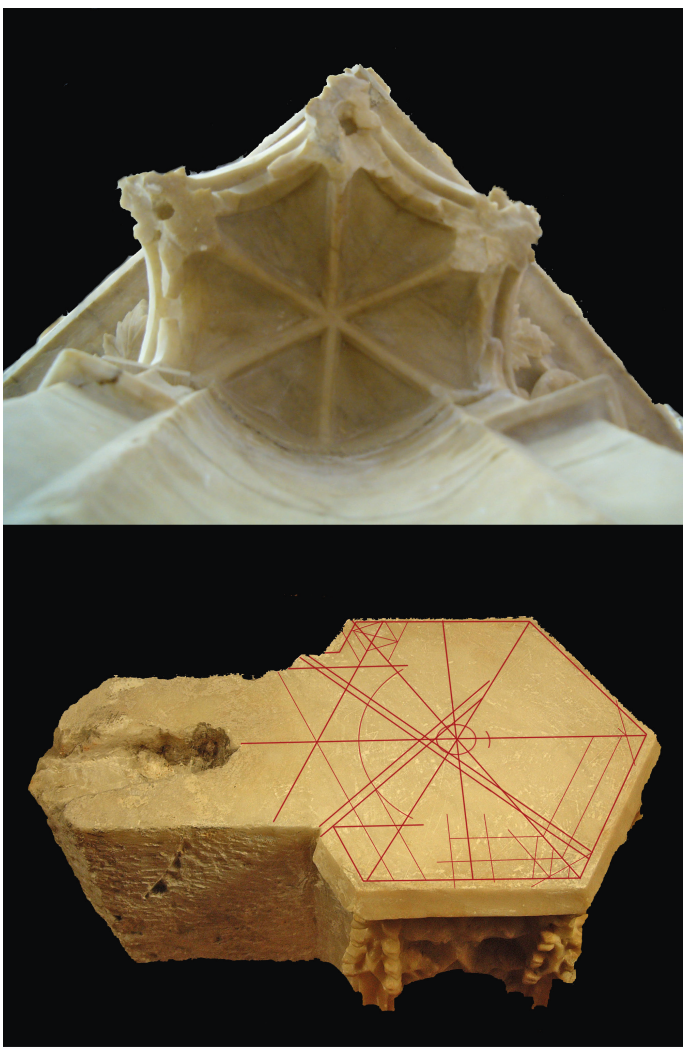

- Fig. 9. Bóveda y referencias gráficas de un dosel situado en el frente de los pies del mausoleo. Fotos de la autora.

crucería sobre planta hexagonal y las huellas para encajar unos remates decorativos perdidos. Sus piezas de alabastro también son enteras, de planta centralizada, prolongan el eje de simetría en dos de sus lados para facilitar su inserción, su montaje en las cuatro esquinas del túmulo, y sus trazos incisos desarrollan mayor riqueza gráfica en todos sus lechos. Una sección circular marca la superficie de la bóveda interna porque, al igual que en la arquitectura real, la mitad de un elemento dibujado bastaba para definir y comprender sus partes fundamentales, y los nervios de su crucería quedan concretizados con dos líneas paralelas ${ }^{38}$. La planta de las pilastras con sus cuadrados, los trazos perimetrales paralelos y los diagonales indican la trayectoria del perfil del vértice del sólido capaz para esculpir el volumen definitivo donde, evidentemente, quedaron sacrifica-

\footnotetext{
${ }^{38}$ Calvo López y Rabasa Díaz, "Construcción, dibujo y geometría", 80-81.
} 


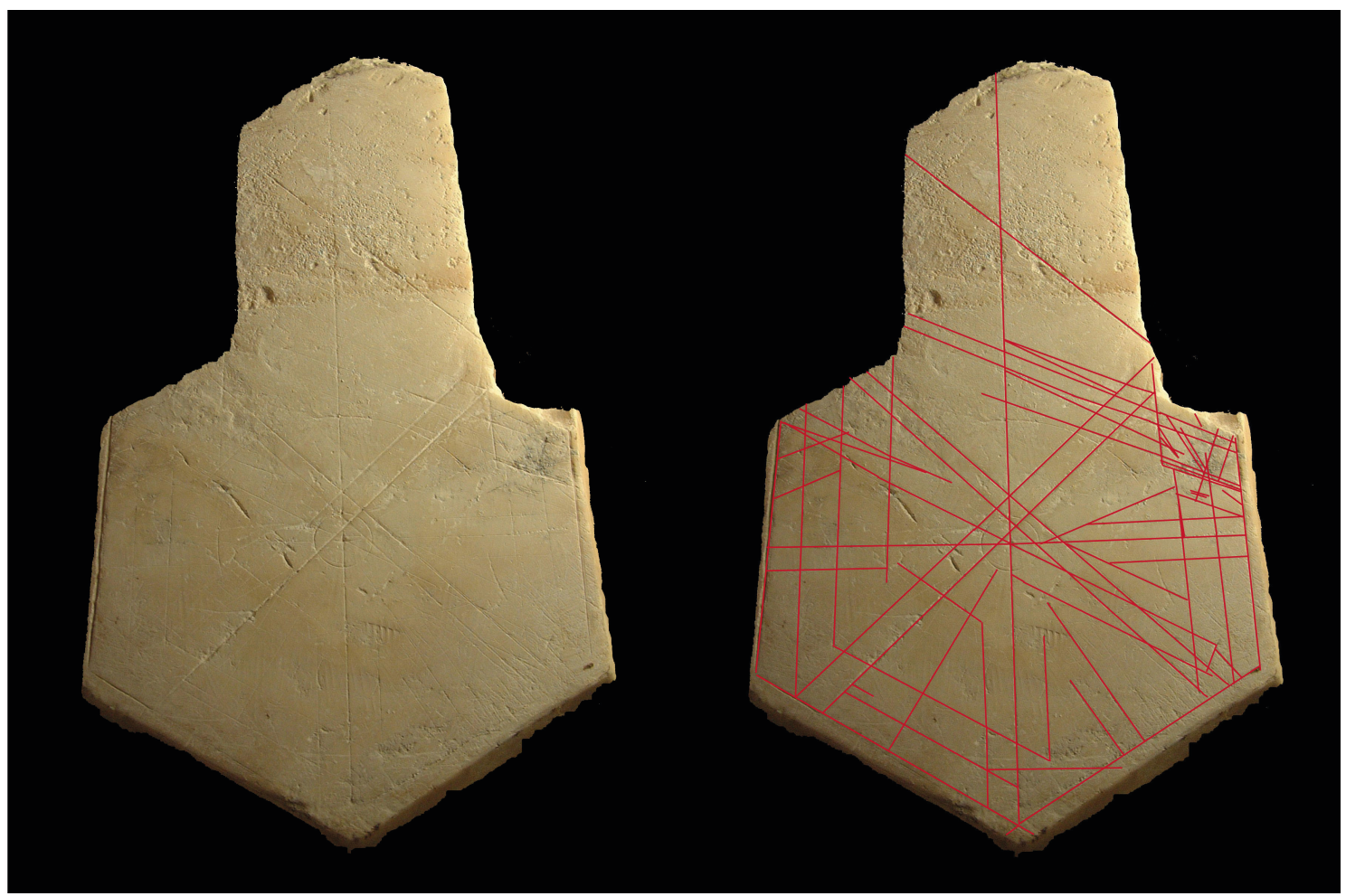

- Fig. 10. Referencias gráficas de los doseles situados en el frente de los pies del mausoleo. Fotos de la autora.

das otras referencias gráficas relativas a los límites y diseño de la microarquitectura exterior (Figs. 9 y 10).

Con el fin de sintetizar las conclusiones de esta investigación debo señalar en primer lugar que las características de todas las referencias gráficas incisas en el sepulcro del cardenal Don Juan de Cervantes responden a dibujos acabados, a ideas maduras delineadas con líneas sencillas, para esculpir la microarquitectura con los mismos resultados conocidos para las construcciones góti$\operatorname{cas}^{39}$. Estos dibujos de ejecución realizados por Lorenzo Mercader necesitaron, para ser llevados a cabo, de las mismas habilidades técnicas desarrolladas en el oficio y creatividad del arquitecto y del escultor gótico en este caso; este conocimiento de la sencilla geometría fabrorum formaba parte del aprendizaje de cada oficio y fue un conocimiento común llevado a cabo por los escultores, los

\footnotetext{
${ }^{39}$ Ruiz de la Rosa, "Dibujos de ejecución. Valor documental", 301-302 y 304-305. Calvo López y Ros Sempere, "Los instrumentos de los canteros", 417-433.
}

entalladores, los imagineros, los orfebres y los carpinteros, entre otros artífices de diversas técnicas artísticas ${ }^{40}$. Sus líneas trazadas a escala real (1:1) sintetizan elementos del diseño aprobado, presentan recursos gráficos necesarios para esculpir el sólido capaz de cada pieza, para llevar a cabo el control formal de la talla, de la ejecución de los elementos escultóricos y del montaje del sepulcro.

Estas referencias demuestran la alta cualificación de Mercadante de Bretaña en la preparación de todo el trabajo escultórico del monumento funerario desde los relativos al diseño, selección del alabastro, al corte y talla escultórica de cada pieza, a la construcción y montaje. Manifiestan sus competencias técnicas para tallar cualquier elemento figurativo teniendo en cuenta las

\footnotetext{
${ }^{40}$ François Bucher, "Micro-Architecture as the 'Idea' of Gothic Theory and Style", Gesta XV/1-2 (1976), 71-89. Jean-Marie Guillouët, "Microarchitectures médiévales. Une perspective historiographique", en Microarchitectures médiévales. L'échelle à l'épreuve de la matière, coord. por Jean-Marie Guillouët (Paris: Picard, 2018), 25-34.
} 
características de los bolos seleccionados, la terminación cromática que tuvieron las distintas superficies de la yacija y del bulto de este sepulcro a mediados del siglo XV.

La calidad artística y el estudio de sus trazados gráficos equipara el sepulcro del cardenal Juan de Cervantes y a su escultor, Lorenzo Mercader, con la gran escultura europea contemporánea y aporta una información importante que facilitará otras investigaciones de escultura monumental y del diseño de su microarquitectura más allá de la epidermis de estos mausoleos al definir perfectamente su contorno, las líneas principales de sus molduras, planos, ejes de simetría y proporciones de cada pieza.

\section{BIBLIOGRAFÍA}

Alonso Ruiz, Begoña. "Las trazas de montea en la construcción gótica: el caso de la montea de la capilla Saldaña". En Arquitectura tardogótica en la corona de Castilla: trayectorias e intercambios, coordinado por Begoña Alonso Ruiz y Fernando Villaseñor Sebastián, 329-344. Sevilla: Editorial Universidad de Sevilla y Universidad de Cantabria, 2014.

Amador de los Ríos, José. Sevilla pintoresca o descripción de sus monumentos artísticos. Sevilla: Colom y Colom, 1844.

Angulo Íñiguez, Diego. "Sepulcro del cardenal Cervantes en la catedral de Sevilla". En La Escultura en Andalucía, fasc. 1. Sevi1la: Laboratorio de Arte, 1928, vol. I.

Angulo Íñiguez, Diego. “Bordados de estilo eyckiano del sepulcro del cardenal Cervantes de la Catedral de Sevilla". En Mélanges Hulin de Loo, 1-4. Bruxelles: Libraire Nationale d'Art et d'Histoire, 1931.

Azcárate Rístori, José María. Colección de documentos para la Historia del Arte en España 2. Datos histórico-artísticos de fines del siglo XV y principios del XVI. Madrid-Zaragoza: Caja de Ahorros de Zaragoza, 1982.
Bucher, François. "Medieval architecture Dessing Methods 800-1560". Gesta, no XI/2 (1972), 37-51.

Bucher, François. "Micro-Architecture as the 'Idea' of Gothic Theory and Style". Gesta, no XV/1-2 (1976), 71-89.

Calvo López, José y Marcos Ros Sempere. "Los instrumentos de los canteros en la transición del gótico al renacimiento". En La arquitectura tardogótica castellana entre Europa y América, coordinado por Begoña Alonso Ruiz, 417-433. Madrid: Silex, 2011.

Calvo López, José y Enrique Rabasa Díaz. "Construcción, dibujo y geometría en la transición entre el Gótico y Renacimiento". Artigrama, 31 (2016), 67-86.

Español Bertrán, Francesca. “El artífice y sus habilidades. La transmisión del conocimiento artístico medieval". En Ver y crear. Obradores y mercados pictóricos en la España gótica (1350-1500), coordinado por Matilde Miquel, Olga Pérez Monzón y Miriam Bueso, 98-113. Madrid: La Ergástula, 2017.

Fuentes Ortiz, Ángel. “La capilla de Gonzalo de Illescas en el monasterio de Guadalupe: un proyecto de Egas Cueman recuperado". Archivo Español de Arte, XC/358 (2017), 113-118.

Gestoso y Pérez, José. Sevilla monumental y artística. Historia y descripción de todos los edificios notables, religiosos y civiles que existen actualmente en esta ciudad y noticia de las preciosidades artísticas y arqueológicas que en ellos se conservan, T. II. Sevilla: Tip. El Conservador, 1890.

Giménez Fernández, Manuel. El retablo mayor de la Catedral de Sevilla y sus artistas. Sevilla: Laboratorio de Arte, 1927.

Gómez-Ferrer Lozano, Mercedes. "La cantería valenciana en la primera mitad del XV: El Maestro Antoni Dalmau y sus vinculaciones con el área mediterránea". Anuario del Departamento de Historia y Teoría del Arte, no 9-10 (1997-1998), 91-106. 
Gómez-Ferrer Lozano, Mercedes. “El maestro de la catedral de Valencia Antoni Dalmau (1435-1453)". En Gothicmed: un museo virtual de la arquitectura gótica mediterránea. http://www.gothicmed.com/ gothicmed/GothicMed/library/maestros/ Antoni-Dalmau

Gómez Moreno, Manuel. “¿Jooskén de Utrech, arquitecto y escultor?". Boletín de la Sociedad Castellana de Excursiones, V (1911), 63-66.

González de León, Félix. Noticia artística, histórica y curiosa de todos los edificios públicos, sagrados y profanos de esta muy Noble, Muy Leal, Muy Heroica e Invicta ciudad de Sevilla, T. II. Sevilla: Imp. José Hidalgo y Cía, 1844.

Goñi Gaztambide, José. "Cervantes, Juan de". En Diccionario de Historia Eclesiástica de España, coordinado por Quintín Aldea Vaquero y Tomás Marín, Suplemento I, 124-128. Madrid: Instituto Enrique Flórez-CSIC, 1987.

Guillouët, Jean-Marie. "Microarchitectures médiévales. Une perspective historiographique". En Microarchitectures médiévales. L'échelle à l'épreuve de la matière, coordinado por Jean-Marie Guillouët, 25-34. Paris: Picard, 2018.

Guillouët, Jean-Marie. Flamboyant architecture and medieval technicality (c. 1400c.1500). Turnhout: Brepols, 2019.

Ibáñez Fernández, Javier. “Entre 'muestras' y 'trazas'. Instrumentos, funciones y evolución de la representación gráfica en el medio artístico hispano entre los siglos XV y XVI. Una aproximación desde la realidad aragonesa". En Arquitectura tardogótica en la Corona de Castilla: trayectorias e intercambios, coordinado por Begoña Alonso Ruiz y Fernando Villaseñor Sebastián, 305-328. Sevilla: Universidad de Sevilla, 2014.

Ibáñez Fernández, Javier. "Hacia un inventario y caracterización de los instrumentos para la proyección, documentación, pre- sentación y ejecución del Gótico en la Península Ibérica entre los siglos XIII y XV". En Trazas, muestras y modelos de tradición gótica en la Península Ibérica entre los siglos XIII y XVI, coordinado por Javier Ibáñez Fernández, 17-80. Madrid: Instituto Juan de Herrera, 2019.

Ibáñez Fernández, Javier y Diego Domínguez Montero. “Antes de Sevilla: Lorenzo Mercader (Mercadante) de Bretaña en Zaragoza (1446-1448). Transferencias e intercambios entre las Coronas de Aragón y Castilla a mediados del siglo XV". Artigrama, no 30 (2015), 169-191.

Ibáñez Fernández, Javier y Arturo Zaragozá Catalán. "Las microarquitecturas y la generación y transmisión de las formas arquitectónicas en el mundo ibérico entre los siglos XIV al XVI". En Sevilla 1514. Arquitectos tardogóticos en la encrucijada, coordinado por Begoña Alonso Ruiz y Juan Clemente Rodríguez Estévez, 411426. Sevilla: Editorial de la Universidad de Sevilla, 2016.

Jiménez Martín, Alfonso. “El otro archivo de la catedral". En Archivos de la Iglesia de Sevilla. Homenaje al archivero D. Pedro Rubio Merino, coordinado por Carmen Álvarez Delgado y Manuel Romero Tallafigo, 753775. Córdoba: Cajasur, 2006.

Jiménez Martín, Alfonso. Anatomía de la catedral de Sevilla. Sevilla: Diputación Provincial, 2013.

Jiménez Martín, Alfonso. “El tamaño sí que importa. Una historia del plano a escala". Artigrama, 31 (2016), 33-65.

Jiménez Martín, Alfonso. “16. Trazado regulador de un tabernáculo de la puerta de la Asunción de la catedral de Sevilla". En Trazas, muestras y modelos de tradición gótica en la Península Ibérica entre los siglos XIII y XVI, coordinado por Javier Ibáñez Fernández, 118-120. Madrid: Instituto Juan de Herrera, 2019.

Jiménez Martín, Alfonso. “20. Monteas de un dosel de la tumba del cardenal Juan 
de Cervantes, en la catedral de Sevilla". En Trazas, muestras y modelos de tradición gótica en la Península Ibérica entre los siglos XIII y XVI, coordinado por Javier Ibáñez Fernández, 122-124. Madrid: Instituto Juan de Herrera, 2019.

Jiménez Sancho, Álvaro y Alfonso Jiménez Martín. “La restauración del sepulcro del cardenal Cervantes de la catedral de Sevilla". En En el umbral de la memoria. Actas de las XIII Jornadas internacionales de intervención en patrimonio histórico-artístico (Logroño, 3-6 noviembre, 2005), 303-315. Logroño: COAR, 2005.

Lafay, Benoît. "Étude et restauration, 20012005". En Les tombeaux des ducs de Bourgogne. Creation, destruction, restauration, coordinado por Françoise Baron, Sophie Jugie y Benoît Lafay, 111-123. Dijon: Somogy Editions d'Art, 2009.

Laguna Paúl, Teresa. "La escultura". En Andalucía Gótica, coordinado por José Fernández López, 66-75. Madrid: Ediciones Encuentro, 1992.

Laguna Paúl, Teresa. “Las portadas del Bautismo y del Nacimiento de la catedral de Sevilla". Bienes Culturales, Revista del Patrimonio Histórico Español, nำ1 (2002), 83101.

Laguna Paúl, Teresa. “The Virgen del Buen Fin in the context of the sculptural oeuvre of Lorenzo Mercadante de Bretaña". En Nicola Jennings y Teresa Laguna, Lorenzo Mercadante de Bretaña. Virgen del Buen Fin, 47-70. Madrid: Coll y Cortes, 2016.

Laguna Paúl, Teresa. "Lorenzo Mercadante de Bretaña (documentado 1446-1468)". En Artistas andaluces y artífices del arte andaluz. El ciclo humanista. Desde el último Gótico al fin del Barroco, coordinado por Clotilde Lechuga Jiménez, 290-325. A Coruña: Publicaciones Comunitarias, 2017.

Laguna Paúl, Teresa. “Un escultor para un cardenal. Lorenzo Mercadante de Bretaña y el sepulcro de Juan de Cervantes: nuevas lecturas documentales".
De Arte, no 16 (2017), 7-30. http://dx.doi. org/10.18002/da.v0i16.5000.

Laguna Paúl, Teresa. "Memoria funeraria y patronazgo de Juan de Cervantes en la catedral de Sevilla. Mercadante de Bretaña y las obras de la capilla de san Hermenegildo". En Obispos y catedrales. Arte en la Castilla Bajo Medieval, coordinado por María Victoria Herráez Ortega, Concepción Cosmen Alonso, María Dolores Teijeira Pablos y José Alberto Moráis Morán, 75-120. Berna: Peter Lang, 2018.

Mestre Navas, Pablo Alberto. “Antiguas letras para un arte nuevo. Escritura, memoria y publicidad en el sepulcro del cardenal Juan de Cervantes (1454-1458). Documenta \& Instrumenta, 17 (2019), 73-95.

Montañés García, Manuel. "Las obras de restauración. Descripción de los ámbitos, patologías y tratamientos realizados". En La catedral de Sigüenza. La puesta en práctica de un Plan Director, 120-200. Madrid: Kalam-Lunwerg, 2006.

Montero Tortajada, Encarna. La transmisión del conocimiento en los oficios artísticos. Valencia, 1370-1450. Valencia: Institución Alfons el Magnanim, 2015.

Pérez Higuera, María Teresa. “Ferrán González y los sepulcros góticos del taller toledano (1385-1410)". Boletín del Seminario de Estudios de Arte y Arqueología, 44 (1978), 129-142.

Rabasa Díaz, Enrique. Forma y construcción en piedra. De la cantería medieval a la estereotomía del siglo XIX. Madrid: Akal, 2000.

Reina Giráldez, Francisco. “Llegada a Sevilla y primeras obras de Lorenzo Mercadante de Bretaña". Archivo Hispalense, no 215 (1985), 143-151.

Rodríguez Estévez, Juan Cemente. Los canteros de la catedral gótica. Del Gótico al Renacimiento. Sevilla: Diputación Provincial, 1998.

Rubio, Germán e Isidoro Acemel. "El maestro Egas en Guadalupe". Boletín de la So- 
ciedad Española de Excursiones, 20/3 (1912), 192-229.

Ruiz de la Rosa, José Antonio. Traza y simetría de la arquitectura. En la Antigüedad y Medioevo. Sevilla: Publicaciones de la Universidad de Sevilla, 1987.

Ruiz de la Rosa, José Antonio. “Diseño de pináculos en la catedral de Sevilla. La justa medida". Periferia, 10 (1991), 9-16.

Ruiz de la Rosa, José Antonio. “Dibujos de ejecución. Valor documental y vía de conocimiento de la catedral de Sevilla". En La catedral de Sevilla. Fundación y fábrica de la obra nueva, coordinado por Alfonso Jiménez Martín, 299-347. Sevilla: Servicio de publicaciones Universidad de Sevilla, 2006.

Serra Desfilis, Amadeo. "El fasto del palacio inacabado. La casa de la ciudad de Valencia en los siglos XIV y XV". En Historia de la ciudad III. Arquitectura y transformación urbana de Valencia, coordinado por Mar Alonso Monterde, Málek Murad Mateu y Francisco Taberner Pastor, 74-98. Valencia: Colegio de Arquitectos de Valencia y Universidad de Valencia, 2004.

Stegmann, Henri y Diego Angulo Íñiguez. La escultura en Occidente. Barcelona: Bruguera, 1936.

Willis, Robert. "On the construction of the vaults of the Middle Ages". Transactions of the RIBA, I/2 (1842), 1-74.
Yarza Luaces, Joaquín. “El artesano medieval en la Edad Media Hispana". En L'ArtistaArtesà Medieval a la Corona d'Aragó: actes : Lleida, 14, 15 i 16 de gener de 1988, coordinado por Joaquín Yarza Luaces y Francesc Fité i Llevot, 7-58. Lérida: Universitat de Lleida, 1999.

Yarza Luaces, Joaquín. "Hombres de poder, gentes del libro, "Viri; Litterati" y encargos artísticos". En El marqués de Santillana (1398-1458), los albores de la España Moderna. El humanista, coordinado por Joaquín Yarza Luaces, 9-34. Hondarrabia: Nerea, 2009.

Zaragozá Catalán, Arturo. “Lenguaje gótico, tradiciones constructivas tardorromanas e inspiración bíblica: consideraciones sobre el gótico mediterráneo y la catedral de Sevilla". En La piedra postrera. V Centenario de la conclusión de la catedral de Sevilla. 1 (Ponencias), coordinado por Alfonso Jiménez Martín, 149-172. Sevilla: Turris Fortissima, 2007.

Zaragozá Catalán, Arturo. “El control de la forma en la arquitectura medieval valenciana: dibujo y oficios artísticos durante los siglos XIII y XIV". En Historia de la ciudad VI: proyecto y complejidad, coordinado por Mar Alonso Monterde, Málek Murad Mateu y Francisco Taberner Pastor, 81101. Valencia: Colegio Oficial de Arquitectos Comunidad de Valencia y CTAV, 2010. 